\title{
Dociekania
}

\section{Ku laboratorium humanistycznemu}

Aleksandra Kil, Jacek Małczyński, Dorota Wolska

TEKSTY DRUGIE 2017, NR 1, S. 274-285

DOI: $10.18318 /$ td.2017.1.23

aboratorium to słowo o tak dużej dziś frekwencji, że Lmożna podejrzewać, iż grozi mu proces semantycznego wyjałowienia albo swoista przeźroczystość. Laboratorium to zarówno miejsce (fizyczna i wyobrażona przestrzeń), społeczno-kulturowa instytucja, jak i metafora przedmiotu i procedur badań humanistycznych. Laboratorium stało się nawet hasłem słownikowym w niemieckim leksykonie kulturoznawczym¹. Pod koniec lat 90. w Antwerpii zorganizowano wystawę poświęconą idei laboratorium. Jak deklarują jej kuratorzy, projekt ten „poszukuje ograniczeń i możliwości miejsc, w których wiedza i kultura są wytwarzane"2. Warto zastanowić się nad tym, jakich przemian symptomem jest laboratoryzacja współczesnej humanistyki. Jej przejawem jest wysyp w ostatnim dziesięcioleciu inicjatyw

1 V. Lehmbrock Laboratorium, w: Über die Praxis des kulturwissensschaftlichen Arbeitens. Ein Handwörtebuch, Hrsg. von U. Frietsch, J. Rogge, Transcript Verlag, Bielefeld 2013, s. 247-249.

2 H.-U. Obrist, B. Vanderlinden Laboratorium, w: Laboratorium, Hrsg. von H.-U. Obrist, B. Vanderlinden, DuPont, Köln 2001, s. 17.
Aleksandra Kil, Jacek Małczyński, Dorota Wolska - reprezentują Laboratorium Humanistyki Współczesnej działające przy Instytucie Kulturoznawstwa Uniwersytetu Wrocławskiego od 2014 roku (www. laboratorium.uni. wroc.pl). Ostatnio opublikowali tom „Prac Kulturoznawczych" pt. Kultura nie-ludzka (2015). Aktualnie w Laboratorium prowadzone są prace nad projektami „Antropocen” oraz "Czego pragną drony?". Kontakt: laboratorium@uni. wroc.pl 
określających się jako laboratoria ${ }^{3}$. Może być to spowodowane cyfryzacją humanistyki, nabywaniem przez humanistów nowych kompetencji technologicznych. Doceniając ten aspekt sprawy, nie stawiamy go w centrum naszych rozważańn

W jakim stopniu laboratoryjne praktyki i wokabularz (eksperyment, doświadczenie, próba, zespołowość, projekt) mogą odmienić humanistykę? $\mathrm{Na}$ czym miałoby polegać eksperymentowanie w humanistyce i kto ponosi za nie odpowiedzialność? Nie jesteśmy w stanie podjąć w tym tekście wszystkich tych wątków ${ }^{5}$. Zajmiemy się przede wszystkim próbą przedstawienia archeologii humanistycznego laboratorium i możliwością pracy zespołowej w humanistyce.

\section{„Dajcie mi laboratorium a poruszę humanistykę"?}

W opublikowanym w 1983 roku artykule Dajcie mi laboratorium, a poruszęświat Bruno Latour twierdził, że laboratorium jest miejscem, w którym na skutek zakłócenia relacji między wnętrzem i zewnętrzem oraz odwrócenia skali z makro na mikro, dokonuje się zmiana układu sił. Latour, tłumacząc mechanizm działania laboratorium, posługuje się metaforą dźwigni'. Przestrzeń

3 Ze względu na niezwykłą obfitość takich inicjatyw w świecie, ograniczamy się do podania polskich przykładów: Laboratorium Cyfrowe Humanistyki na Uniwersytecie Warszawskim, laboratoria na Wydziale Artes Liberales Uniwersytetu Warszawskiego (m.in. Laboratorium Romantyczne, Semiotyczne, Filhelleńskie), laboratorium twórczego programowania kierowane przez Piotra Mareckiego na Uniwersytecie Jagiellońskim, Laboratorium Humanistyki Współczesnej przy Instytucie Kulturoznawstwa Uniwersytetu Wrocławskiego, Medialab w Katowicach, czasopismo "Laboratorium Kultury" wydawane na Uniwersytecie Śląskim oraz Miasto Przyszłości/ Laboratorium Wrocław w ramach Europejskiej Stolicy Kultury Wrocław 2016.

4 Zob. A.E. Earhart The Digital Humanities as a Laboratory, w: Between Humanities and the Digital, ed. by P. Svensson, D.T. Goldberg, The MIT Press, Cambridge, MA 2015, s. 391-400. Książkę poświęconą krytycznej genealogii laboratoriów medialnych (zatytułowaną roboczo The Lab Book) przygotowują także J. Parikka, L. Emerson i D. Wershler - zob. http://whatisamedialab. $\mathrm{com} /(27.07 .2016)$.

5 Powszechnie utożsamia się laboratorium z przestrzenią eksperymentowania. Tzw. nowy eksperymentalizm jest dowodem na to, że w przyrodoznawstwie eksperyment jest przedmiotem żywych dyskusji i poznawczych przewartościowań (zob. Nowy eksperymentalizm - teoretycyzm - reprezentacja, red. D. Sobczyńska, P. Zeidler, Wydawnictwo Naukowe Instytutu Filozofii UAM, Poznań 1994). Eksperyment stanowi również wyzwanie dla humanistów warte osobnego opracowania.

6 B. Latour Dajcie mi laboratorium a poruszę świat, przeł. K. Abriszewski, Ł. Afeltowicz, „Teksty Drugie" $2009 \mathrm{nr} 1 / 2$, s. 163-192. 
laboratorium jest przestrzenią kontroli, wielokrotnych prób i błądzenia. $\mathrm{Pa}-$ rafrazując tytuł artykułu Latoura, chcemy włączyć się do dyskusji nad tym, czy laboratorium ma rację bytu w humanistyce i czy mogłoby odegrać równie kluczową rolę w czasach kryzysu uniwersytetu nowoczesnego. Czy istnieje inny niż tekst ekwiwalent humanistycznego laboratorium? Czy laboratoryjność w humanistyce ogranicza się do pracy tekstem?? Odpowiedź na to pytanie będzie uzależniona od przyjmowanej perspektywy. Czym innym jest laboratorium dla literaturoznawcy ${ }^{8}$, historyka ${ }^{9}$, kulturoznawcy czy antropologa kulturowego ${ }^{10}$.

Latour przeciwstawia dwie figury: naukowca i polityka:

Polityk nie ma laboratorium, a naukowiec je posiada. Tak więc polityk działa zawsze w świecie, którego skala jest pełna, mając za każdym razem tylko jedno podejście, pozostając zawsze na świeczniku. Musi sobie radzić - wygrywać lub przegrywać „tam na zewnątrz”. Naukowiec posługuje się modelami o zmodyfikowanej skali, a mnożąc błędy w swoim laboratorium pozostaje w ukryciu przed kontrolującymi oczyma publiczności. Może próbować tyle razy, ile sobie życzy i przedstawić swoje wyniki dopiero wtedy, gdy popełnił wszystkie niezbędne błędy, dzięki którym uzyskał „pewność"."

7 O "pracy tekstem" i tekście jako laboratorium pisał Ryszard Nycz W stronę innowacyjnej humanistyki polonistycznej: tekst jako laboratorium. Tradycje, hipotezy, propozycje, w: Przyszłość polonistyki. Koncepcje - rewizje - przemiany, red. A. Dziadek, K. Kłosiński, F. Mazurkiewicz, Wydawnictwo UŚ, Katowice 2013, s. 105-124.

8 Zob. np. A. Żychliński Laboratorium antropofikcji. Dociekania filologiczne, Wydawnictwo IBL PAN oraz Wydawnictwo Naukowe UAM, Warszawa-Poznań 2014, R. Sendyka Od kultury "ja” do kultury "siebie”. O zwrotnych formach w projektach tożsamościowych, Universitas, Kraków 2015, S. $153,323$.

O laboratorium historyków w kontekście mikrohistorii pisał Rafał Nahirny Losy naukowej łamigłówki. Clifford Geertz, mikrohistorie i podmiotowość, Wydawnictwo UWr, Wrocław 2011, s. 92-101. Swą pracę mianem "historycznego laboratorium” określała Natalie Zemon Davis Powrót Martina Guerre'a, przeł. P. Szulgit, Zysk i S-ka, Poznań 2011, s. 16. Por. T. Wiślicz Eksperyment w badaniu historycznym, w: Historia-dziś. Teoretyczne problemy wiedzy o przeszłości, red. E. Domańska, R. Stobiecki, T. Wiślicz, Universitas, Kraków 2014, s. 59-66.

Nie zajmujemy się w tym miejscu kwestią relacji między naukami humanistycznymi i społecznymi. W tym drugim przypadku należałoby uwzględnić np. eksperymenty prowadzone przez Philipa Zimbardo. 
Jaką rolę odgrywa humanistyka - czy bliżej jej do naukowca czy polityka? A być może stanowi ona osobną figurę? Czy humanistyka posiada laboratorium? Czy - tak, jak naukowiec - dysponuje przestrzenią metodycznego błądzenia? Tym, co naszym zdaniem umyka Latourowi w charakterystyce laboratorium, jest kwestia odpowiedzialności. Latour przechodzi obojętnie np. nad doświadczeniami na zwierzętach. Tymczasem, jak wiadomo, konotacje eksperymentów dotyczących ludzi i kultur budzą uzasadniony niepokój i kierują myśl ku wątkom faustycznym.

Zdaniem Latoura, gdy naukowiec opuszcza laboratorium, traci grunt pod nogami. „Gdy [naukowcy] naprawdę wychodzą «na zewnątrz» - pisze Latour - nie wiedzą nic, blefują, zawodzą, muszą kombinować, tracą wszelką możliwość powiedzenia czegokolwiek, co natychmiast nie zostałoby zaatakowane przez mrowie równie uprawnionych stwierdzeń"12. Podobnie naszym zdaniem dzieje się w przypadku humanisty, który angażuje się w życie społeczno-polityczne. Nie chodzi nam o to, że humanista nie powinien wychodzić "na zewnątrz" swojego potencjalnego laboratorium. Co więcej, dostrzegamy, że opozycja wnętrze - zewnętrze u Latoura ma charakter aporii. Jeśli humanista wychodzi na zewnątrz, to - tak, jak naukowiec - powinien zabrać ze sobą swoje laboratorium. W przeciwnym razie, tak jak naukowiec, straci solidny grunt pod nogami. Parafrazując Adorno, warto pamiętać, że aby wyjść na zewnątrz, trzeba być w środku ${ }^{13}$.

\section{$\mathbf{Z}$ archeologii laboratorium humanistycznego}

Chcielibyśmy wyraźnie rozróżnić kwestie laboratorium w humanistyce oraz laboratorium humanistycznego. Pojęcie laboratorium zadomowiło się już w humanistyce za sprawą badań społeczno-kulturowego wymiaru nauki oraz etnografii laboratorium, które odczarowały laboratorium, wcześniej rozumiane jako neutralna sceneria pracy naukowej ${ }^{14}$. Wciąż niewiele wiadomo jednak o laboratorium humanistycznym; czym jest, czym

12 Tamże, s. 189.

13 T. Adorno Vorlesungen über Negative Dialektik, Suhrkamp Verlag, Frankfurt am Main 2003.

14 B. Latour, S. Woolgar Laboratory Life. The Construction of Scientific Facts, Princeton University Press, Princeton, New Jersey 1986. Zob. także: Studia nad naukq i technologiq. Wybór tekstów, red. E. Bińczyk, A. Derra, Wydawnictwo UMK, Toruń 2014 oraz Ł. Afeltowicz Laboratoria $w$ działaniu. Innowacja technologiczna w świetle antropologii nauki, Oficyna Naukowa, Warszawa 2011. 
miałoby być. Jego historia, a wolelibyśmy powiedzieć - archeologia, nie została jeszcze napisana. Można by ją było rozpocząć od swoistego archetypu laboratorium, jakim jest pracownia alchemiczna. Jakkolwiek laboratorium od zarania powiązane jest z naukami przyrodniczymi, to jego początki odsyłają do późnośredniowiecznej i wczesnorenesansowej alchemii15. Oczywiście można tam szukać prefiguracji nauk przyrodniczych, ale z dzisiejszej perspektywy, zarówno posthumanistycznej, jak i konstruktywistycznej, pracownia alchemiczna wydaje się ciekawsza jako miejsce wypracowywania drogą eksperymentów, nie - procedur mimetycznych, pojęciowego obrazu natury, który, używając właśnie rodzącej się terminologii i być może dokonując niewielkiego nadużycia, moglibyśmy nazwać naturo-kulturą ${ }^{16}$.

Nie ma pewności co do tego, że odwołanie do zapomnianej tradycji laboratorium humanistycznego mogłoby okazać się pomocne w krystalizacji jego współczesnego sensu. Jakkolwiek tacy myśliciele jak Charles Sanders Peirce, Aby Warburg i Claude Lévi-Strauss wprost identyfikowali swoją aktywność z konceptem laboratorium, to warto pamiętać, że niejednako je rozumieli i uprawiali swą intelektualną aktywność w innych od naszych warunkach.

Aby Warburg sięgnął po metaforykę laboratoryjną w monumentalnym Erneurung die heidnische Antike:

Jednocześnie intencją było pokazanie na przykładzie ścisłego [positive] badania, jak metoda nauki o kulturze może być wzmocniona dzięki przymierzu historii sztuki i religioznawstwa. Niedostatki tego wstępnego eksperymentu są dla samego autora aż zanadto oczywiste [...] Niech historia sztuki i studia nad religią [...] dzielą stół warsztatowy w laboratorium kulturoznawczej historii obrazów. ${ }^{17}$

15 V. Lehmbrock Laboratorium..., S. 245; Ł. Afeltowicz, R. Sojak Arystokraci i rzemieślnicy. Synergia stylów badawczych, Wydawnictwo UMK, Toruń 2015, s. 195-233.

16 Por. E. Chojecka Obraz natury "drugiego obiegu" - wizja alchemiczna, w: Sztuka a natura. Materiały XXVIII Sesji Naukowej Stowarzyszenia Historyków Sztuki przeprowadzonej 23-25 listopada 1989 roku w Katowicach, Oddział Górnośląski Stowarzyszenia Historyków Sztuki, Katowice 1991, s. 81-87.

17 A. Warburg The Renewal of Pagan Antiquity. Contributions to the Cultural History of the European Renaissance, trans. by D. Britt, Getty Research Institute for the History of Art and the Humanities, Los Angeles 1999, s. 650-651. 
Warburg utożsamiał zatem kulturoznawczą naukę o obrazach z ideą laboratorium, na co zwracają uwagę komentatorzy jego prac ${ }^{18}$.

Peirce obstawał przy uprawianiu filozofii laboratoryjnej, odróżniając ją od filozofii seminaryjnej ${ }^{19}$. Oba sposoby refleksji dzieli nie przedmiot rozważań, ale metoda. Filozofia laboratoryjna unika wysokiego stopnia ogólności i abstrakcji. W ujęciu Peirce'a filozofowanie to identyfikacja tego, co w naszym myśleniu narzuca się jako wyraz zdrowego rozsądku, doxa, przyjmowany obraz świata. Dlatego Peirce powtarzał za Arystotelesem: musimy filozofować, żeby nie filozofować. Filozofowanie nie musi zawsze prowadzić do krytyki i odrzucenia tkwiących w nas głęboko założeń, ale pozwala je wydobyć i naświetlić. Tym samym chroni przed bezwolnym zawierzeniem doktrynom i aksjomatom. Laboratoryjna filozofia eksperymentuje więc nieustająco z naszym zdrowym rozsądkiem, co prowadzi albo do filozofii analitycznej, albo do hermeneutyki przedsądów.

Do instytucjonalnego znaczenia laboratorium sięgał Lévi-Strauss. Jego Laboratorium Antropologii Społecznej zostało założone w 196o roku i miało swoją siedzibę w Collège de France (początkowo mieściło się w Musée Guimet). „Niektórzy dziwią się - pisał Lévi-Strauss - że termin laboratorium może być stosowany w centrum nauk humanistycznych. Stosując go, nie ulegamy jednak modzie czy fałszywemu podobieństwu. Zgodnie z etymologią, laboratorium jest najpierw miejscem, w którym się pracuje. Wystarczy zatem dostać się do naszego [laboratorium], żeby stwierdzić, że metody badań etnologicznych przyjmują dzisiaj styl, który zbliża je do tych z obszarów bardziej zaawansowanych"20. W laboratorium odbywały się seminaria Lévi-Straussa, wydawano czasopismo "L'Homme” oraz prowadzono prace badawcze. Jego członkowie brali udział w badaniach terenowych, które miały stanowić ekwiwalent - jak pisze jedna z laborantek - eksperymentów przeprowadzanych przez przyrodoznawców. Ponadto praca w Laboratorium polegała na analizie

18 Np. P. van Huisstede Der Mnemosyne-Atlas. Ein Laboratorium der Bildgeschichte, w: Aby M. Warburg »ekstatische Nymphe... trauernder Flussgott«. Portrait eines Gelehrten, Hrsg. von R. Galitz, B. Reimers, Dolling und Galitz Verlag, Hamburg 1995, s. 130-172; Ch.D. Johnson Memory, Metaphor, and Aby Warburg's Atlas of Images, Cornell University Press, Ithaca, New York 2012, s. 76-89.

Ch.S. Peirce Laboratory and Seminary Philosophies, w: tegoż The Collected Papers, t. 1: Principles of Philosophy, 1931, http://www.textlog.de/4252.html (27.07.2016).

20 Cyt. za: N. Belmont Le Laboratoire d'anthropologie sociale, "La Lettre du Collège de France", Hors sèrie, Novembre 2008, s. 62, http://lettre-cdf.revues.org/237?lang=en (27.07.2016). 
fiszek Human Relations Area Files umożliwiających międzykulturowe badania porównawcze ${ }^{21}$.

Przywołane przez nas przykłady łączy swoiście pojmowana eksperymentalność. W przypadku Peirce'a można mówić bowiem o metodzie eksperymentalnej - sam filozof swoją analizę pojęć zestawiał przenośnie z analizą chemiczną, a sensem filozofii laboratoryjnej była antydogmatyczność, szukanie nieutartych ścieżek myśli. Warburg, którego „bezimienną naukę"22 nazywano laboratorium, wykazywał się eksperymentalnością w przynajmniej dwóch wymiarach: po pierwsze, formułował nowe propozycje teoretyczne i metodologiczne, szkicując podstawy dla interdyscyplinarnej Bildwissenschaft; po drugie, wykorzystywał do tego nowe instrumenty i techniki poznawcze (przenośne tablice atlasu Mnemosyne zawierające kompilacje obrazów i teksty). Zresztą oba te wymiary można też dostrzec w pracach Lévi-Straussa. Realizację scjentystycznych dążeń humanistyki być może najłatwiej dojrzeć w Laboratorium Lévi-Straussa czy refleksji Peirce'a. Humanistyka eksperymentalna najpełniej objawiałaby się w formie Warburgiańskiej ikonologii.

\section{Laboratoryzacja humanistyki?}

Zarysowana próbka archeologii humanistycznego laboratorium sugeruje, że idea laboratorium pojawia się w humanistyce wówczas, gdy podejmuje ona starania o prestiż i umocnienie swojego autorytetu. Tu warto zwrócić uwagę na pewną właściwość, by nie powiedzieć niebezpieczeństwo, metaforyki laboratoryjnej. Oto często mamy do czynienia ze „wzmacnianiem” humanistyki autorytetem nie własnym, lecz zapożyczonym z nauk ścisłych i przyrodoznawstwa. Do przeciwników tej metafory należał np. Clifford Geertz. W Opisie gęstym argumentował, że w „naturalnym” laboratorium etnograficznym nie ma możliwości manipulowania parametrami oraz że laboratorium tworzy iluzję czystych faktów. Geertz obawiał się laboratoryzacji humanistyki ze względu na popularność scjentyzmu, którego przejawem był boom strukturalistyczny. Czy idea laboratorium może być użyteczna w określaniu specyfiki i charakteru humanistyki bez przyrodoznawczych odwołań i porównań?

Ze wspomnianego niebezpieczeństwa zdają sobie sprawę Stephen Collier, Andrew Lakoff i Paul Rabinow, którzy w 2006 roku powołali Laboratorium

21 Tamże.

22 Zob. G. Agamben Aby Warburg i „nauka bezimienna”, przeł. K. Rutkowski, "Konteksty. Polska Sztuka Ludowa" $2007 \mathrm{nr}$ 3/4, s. 277. 
Antropologii Współczesności. Odróżniają oni laboratorium przyrodoznawcze i humanistyczne ze względu na inne cele, formy materialno-instytucjonalne, codzienne praktyki, autorstwo i oryginalność, formy współpracy z innymi badaczami oraz stosunek do badanych obiektów ${ }^{23}$. Świadectwo intelektualnej drogi Rabinowa wiodącej ku idei laboratorium stanowi tekst Steps toward an anthropological laboratory ${ }^{24}$. Czytając ten osobisty tekst Rabinowa, odnieśliśmy wrażenie, że zainicjowane przez niego laboratorium antropologiczne jest wyrazem tęsknoty za większym rygorem i pracą zespołową; próbą wynalezienia nowych form badania, pisania oraz nowego etosu dla antropologii współczesności. Być może popularność, jaką cieszy się we współczesnej humanistyce pojęcie laboratorium, jest jednym z symptomów głębszych przemian „paradygmatycznych"; odchodzenia od hermeneutyki ku czemuś jeszcze nierozpoznanemu.

Jak zauważył Rabinow, Writing Culture nie tylko zrewidowała autorytet antropologicznej teorii, ale też - paradoksalnie - wzmocniła autorytet antropologa jako autora i zarazem bohatera opowieści etnograficznych. Badacze, którzy podważali autorytet teorii, sami - tak jak Geertz - stali się autorytetami odznaczającymi się indywidualistycznym stylem pisarskim (Rabinow mówi nawet w tym kontekście o antropologach-gwiazdorach czy bohaterach) ${ }^{25}$. Wyczerpanie się eksperymentów pisarsko-badawczych, do których zachęcał zwrot interpretatywny, było kolejnym powodem, dla którego Rabinow wraz z Collierem i Lakoffem spróbowali uprawiać antropologię laboratoryjną, widząc w niej antidotum na słabości awangardy antropologicznej po Writing Culture. Swoje Laboratorium określili mianem secesjonistycznego; mniej zainteresowanego szlifowaniem rozpoznawalnego, indywidualnego stylu badań i pisania, raczej nastawionego na zespołową pracę nad pojęciami, pracę cechującą się pewnym rygorem, w wyniku której powstaną kryteria intersubiektywnej sprawdzalności pojęć.

23 S.J. Collier, A. Lakoff, P. Rabinow What is laboratory in the human sciences?, „ARC Working Paper" 2006 No. 1, http://anthropos-lab.net/wp/publications/2007/08/workingpaperno1.pdf (27.07.2016).

24 P. Rabinow Steps toward an anthropological laboratory, "ARC Concept Note” 2006 No. 1, http:// anthropos-lab.net/wp/publications/2007/08/conceptnoteno1.pdf (27.07.2016).

Rabinow wspomina swą współpracę z Geertzem, w ramach której miał nadzieję na uczestnictwo w zbiorowym projekcie badawczym w Maroku. Forma tej współpracy była dla niego rozczarowująca i drogi Geertza i Rabinowa rozeszły się. Geertz odradzał później Rabinowowi publikację książki Refleksje na temat badań terenowych w Maroku. Zob. P. Rabinow Steps..., s. 7-9. 


\section{Praca zbiorowa: „zebrana" czy zespołowa?}

Collier, Lakoff i Rabinow odróżnili dwa style współpracy: collected work i collective work. Pierwszy z nich proponujemy przełożyć jako "praca zebrana”. Wiąże się on z dominującym w humanistyce modelem indywidualistycznym, a jego wynikiem są np. publikacje w tomach pokonferencyjnych. Drugi, „praca zespołowa", łączy się z modelem laboratoryjnym i przejawia pod postacią intensywnej i burzliwej wymiany myśli. Nawiązując do tego rozróżnienia, chcielibyśmy wskazać dwie strategie określania współautorstwa. W przypadku „pracy zebranej” eksponuje się redaktora lub jednego, najbardziej prominentnego ze współautorów ${ }^{26}$. W przypadku „pracy zespołowej” zamiast indywidualnych autorów podaje się nazwę zespołu ${ }^{27}$. W trakcie pracy nad tym tekstem sami zastanawialiśmy się, czy zdobylibyśmy się na zespołowe określenie jego autorstwa i sygnowanie go „Laboratorium Humanistyki Współczesnej”. Bez wątpienia natknęlibyśmy się na rozmaite przeszkody: kwestie parametryzacji, wydawnicze (np. czyja nota biograficzna), ekonomiczne, a także osobowościowe i etyczne. Za tymi trudnościami stoi określony wzór kulturowy regulujący kwestie autorstwa w dziedzinie intelektualnej aktywności (kwalifikowanej i waloryzowanej w ramach tego wzoru jako indywidualna twórczość). Problem „zbiorowego” autorstwa pojawia się w humanistyce głównie, gdy mówi się o nierzetelności i nieuczciwości intelektualnej. Czy popularność idei laboratorium może być potraktowana jako symptom transformacji tej kulturowej regulacji?

Zespołowość pracy jako charakterystyczna dla aktywności laboratoryjnej stanowi wyjątkowe wyzwanie dla laboratorium humanistycznego. Może być ona rozpatrywana w różnych perspektywach: epistemologicznej (zbiorowy podmiot poznania), społecznej (hierarchiczność, egalitarność, stosunki władzy), afektywnej (charakter więzi i ich napięć), pragmatycznej (organizacja wspólnej pracy i jej pozapoznawczy cel), materialistycznej („myślenie za pomocą rąk i oczu"28 , rekwizyty, aranżacja przestrzeni) i, last but not least,

26 Np. okładka książki Samobójstwo oświecenia? Jakneuronauka i nowe technologie pustoszą ludzki świat sygnowana: Andrzej Zybertowicz z zespołem.

27 Zob. np. artykułMessy Shapes of Knowledge - STS Explores Informatization, New Media, and Academic Work sygnowany jako The Virtual Knowledge Studio (w: The Handbook of Science and Technology Studies, ed. by E.J. Hackett i in., The MIT Press, Cambridge, MA 2008, s. 319-353). W tym przypadku nazwiska autorów zostały podane w przypisie. Nie wiadomo jednak, jaką przyjęto zasadę, ponieważ nazwiska nie pojawiają się w porządku alfabetycznym.

28 B. Latour Wizualizacja i poznanie: zrysowanie rzeczy razem, przeł. A. Derra, M. Frąckowiak, "Avant" 2012 nr 3, s. 207-257. 
etycznej (zaufanie, szczerość, uczciwość i odpowiedzialność intelektualna). Zarówno Lévi-Strauss, jak i Warburg, projektując swe laboratoria, dostrzegali znaczenie wiedzy zdobywanej kolektywnie. W humanistyce dominuje model indywidualistyczny, model pracy samotniczej. Jakkolwiek wielu autorów argumentuje, że nigdy nie pracuje się tu samotnie ${ }^{29}$, o czym świadczą choćby przypisy i rozbudowane sekcje podziękowań, a także liczne dzieła łączące rozprawy wielu autorów - nie tylko wspólną okładką, choć takie zdają się dominować - to problem humanistycznej pracy zespołowej wydaje się, jeśli nie niemożliwy, to na pewno nietypowy czy peryferyjny. Na czym zatem miałaby polegać laboratoryjna współpraca, czym różni się od innych form akademickiego współdziałania, np. pracy w ramach teoretycznej szkoły, zakładu, katedry czy form współpracy pozaakademickiej angażującej akademików, $n p$. think tanku. Tę formę przywołuje Rabinow, charakteryzując via negativa laboratorium; laboratorium nie tyle rozwiązuje problemy generowane przez porządki społeczno-kulturowe, co porządki te problematyzuje.

\section{Współmyślność}

Warunkiem współpracy w wielu intelektualnych przedsięwzięciach jest pewien rodzaj jednomyślności, np. zgody co do idei wiodącej, paradygmatu, założeń. Natomiast w przypadku laboratorium, ze względu na jego programową otwartość, istotniejszy od jednomyślności wydaje się nam imperatyw stworzenia warunków do tego, co proponujemy nazwać współmyśleniem. W związku z tym współmyślność nie jest stanem, lecz raczej momentem czy zbiorem takich momentów twórczej, efektywnej intelektualnej współpracy. Współmyślność jest przygodna, efemeryczna, zdarzeniowa, trudna do uchwycenia i nie ma gwarancji, że zawsze się uda. Ten rodzaj współpracy wymaga zaufania i chęci bezinteresownego dzielenia się wiedzą, jakkolwiek prostodusznie to brzmi. Współmyślność nie musi być też rozumiana jako praca synchroniczna, dająca się zlokalizować interakcja kilkorga badaczy. Laboratorium jest raczej modusem pracy naukowej niż jej fizycznym miejscem, chociaż wagi układów przestrzennych (np. ustawiania stołu w pracowni) nie sposób zlekceważyć.

29 Zob. A. Grafton Worlds made by words: scholarship and community in the modern West, Harvard University Press, Harvard 2011; W. McCarty Humanities Computing, Palgrave Macmillan, Basingstoke 2005, S. 10-14; P. Svensson From optical fibre to conceptual infrastructure, "Digital Humanities Quaterly" 2011 Vol. 5, No. 1, http://www.digitalhumanities.org/dhq/vol/5/1/00009o/000090. html (27.07.2016). 
Te nasze intuicje dotyczące współmyślności wspiera pewien eksperyment wspomnianego już Laboratorium Antropologii Współczesności, mianowicie praktykowane w jego ramach na Uniwersytecie w Berkeley (pod opieką Rabinowa) labinarium. Chodzi o formę zajęć łączących cechy seminarium i laboratorium.

W autokomentarzu do labinaryjnej współpracy autorstwa Trine Mygind Korsby i Anthony'ego Stavrianakisa podniesiono kwestie dotyczące jej temporalności, afektywności i materialności ${ }^{30}$. Poddając refleksji własne doświadczenia współmyślności, zauważyliśmy, że wspomniane wymiary bywały znaczące także dla naszego laboratorium, chociaż łatwo było przejść nad nimi do porządku dziennego, nie dostrzegając ich epistemicznej doniosłości. Ponadto, w tekście Korsby i Stavrianakisa zwrócono uwagę na problem tzw. krytycznej de-subiektywizacji myślenia. Nie oznacza ona neutralizacji czynnika subiektywnego w procesie produkcji wiedzy, lecz jak twierdzi Rabinow, wręcz przeciwnie, krytyczne rozpoznanie stosunków władzy w ich afektywnym wymiarze. Relacje sił i afekty stają się centralnym przedmiotem uwagi, jako te czynniki, które warunkują możliwości i wolę współpracy bądź jej brak.

Za jednego z patronów tego rodzaju przedsięwzięć wspomniani autorzy uznają Rolanda Barthes'a. Także my w tekście Barthes'a dedykowanym seminarium $^{31}$ rozpoznajemy bliski nam model laboratoryjnej współpracy. Seminarium jest kameralne, intymne, jest przestrzenią zarówno realną, jak i wyobrażoną, o swoistej proksemice. Opisując panujące na nim relacje międzyludzkie, Barthes przywołuje Fourierowski model falansteru, oparty na idei równości. Ideał ten zakładał wytwarzanie różnic, które, co podkreślał Barthes, nie prowadzą do konfliktu, lecz wykształcania oryginalności. Nie oznacza ono jednak rywalizacji i walki o prestiż. Seminarium nie jest przestrzenią nieuregulowaną, ale też nie jest przestrzenią nadzoru.

Przypomnijmy na koniec, że Bruno Latour traktował laboratorium jako dźwignię. Po ten sam trop (mochlos) sięga też Jacques Derrida w rozważaniach

30 T.M. Korsby, A. Stavrianakis Moments in Collaboration: Experiments in Concept Work, "Ethnos. Journal of Anthropology" 2016, http://dx.doi.org/10.1080/00141844.2015.1137606 (27.07.2016).

R. Barthes To the Seminar, w: tegoż The Rustle of Language, trans. by R. Howard, University of California Press, Berkeley 1989, s. 332-342. Tytuł eseju Barthes'a (Au seminaire) jest trudny do przetłumaczenia na język polski. Oznacza zarówno okolicznik miejsca (kierunek), encomium (pochwałę, uznanie) oraz dedykację. Można byłoby tłumaczyć go zatem: Do seminarium, Na seminarium, Ku seminarium, Dla seminarium lub Pochwała seminarium. Podobna intencja towarzyszy tytułowi naszego tekstu. 
o kryzysie nowoczesnego uniwersytetu ${ }^{32}$. Pracownia laboratoryjna jawi się jako możliwe antidotum na ten kryzys. Laboratorium może stanowić odpowiedź na, mówiąc językiem Derridy, destrukcyjną inwazję zewnętrza uniwersyteckiego. Chodzi o otwartość laboratorium wobec życia pozauniwersyteckiego, jego personalną egalitarność, a także możliwość powiązania z ograniczonymi w czasie projektami. Stanowi ono także swoisty punkt wewnątrzinstytucjonalnego oporu. Laboratoria humanistyczne nie rozwiążą problemów, ale mogą spełnić rolę mochlos i wyrwać nas z kolein oraz rutyny, jaka jest naszym udziałem, ku możliwościom jeszcze ostatecznie nieupostaciowanym.

\section{Abstract}

\section{Aleksandra Kil, Jacek Małczyński, Dorota Wolska}

UNIVERSITY OF WARSAW

Towards a Humanistic Laboratory

This article is an attempt to think about the 'laboratization' of the humanities on the metalevel. Building on Bruno Latour's essay 'Give Me a Laboratory and I Will Move the World,' the authors explore if and how the laboratory can renew the humanities. They differentiate between the laboratory in the humanities and the humanistic laboratory and present an archaeology of the humanistic laboratory (Charles Peirce, Aby Warburg, Claude Lévi-Strauss). Considering the possibilities of teamwork in the humanities, they conclude that this is the least well researched subject, proposing the concept of 'teamthinking' as the most important expression of laboratory teamwork. Finally, the authors suggest that the laboratory can be a locus of resistance in the university system or within individual institutions in times of crisis.

\section{Keywords}

humanistic laboratory, labinarium, teamwork, team-thinking

32 J. Derrida Mochlos; or The Conflict of the Faculties, trans. by R. Rand, A. Wygant, w: Logomachia: The Conflict of the Faculties, ed. by R. Rand, University of Nebraska Press, Lincoln-London 1992, s. 1-34. 